\title{
Meningiomas: An Overview of the Landscape of Copy Number Alterations in Samples from an Admixed Population
}

\author{
Michele Amaral da Silveira,, ${ }^{1,2}$ Wallax Augusto Silva Ferreira, ${ }^{1,2}$ \\ Carolina Koury Nassar Amorim, ${ }^{2}$ José Reginaldo Nascimento Brito, ${ }^{3}$ André Salim Kayath, \\ Fernanda do Espirito Santo Sagica, ${ }^{2}$ and Edivaldo Herculano Corrêa de Oliveira $\mathbb{D}^{2,5}$ \\ ${ }^{1}$ Programa de Pós-Graduação em Neurociências e Biologia Celular, ICB, UFPA, Rua Augusto Correa, 01, Belém, \\ PA 66075-990, Brazil \\ ${ }^{2}$ Laboratório de Cultura de Tecidos e Citogenética, Seção de Meio Ambiente, Instituto Evandro Chagas, \\ BR $316 \mathrm{Km}$ 7, s/n Levilândia, Ananindeua, PA, Brazil \\ ${ }^{3}$ Programa de Pós-Graduação em Oncologia e Ciências Médicas, NPO, Universidade Federal do Pará (UFPA), \\ Rua dos Mundurucus 4487, Belém, PA, Brazil \\ ${ }^{4}$ Núcleo de Pesquisas Oncológicas, Universidade Federal do Pará (UFPA), Rua dos Mundurucus 4487, Belém, PA, Brazil \\ ${ }^{5}$ Faculdade de Ciências Exatas e Naturais, ICEN, Universidade Federal do Pará, Rua Augusto Correa, 01, Belém, \\ PA 66075-990, Brazil \\ Correspondence should be addressed to Edivaldo Herculano Corrêa de Oliveira; ehco@ufpa.br
}

Received 28 February 2020; Accepted 22 May 2020; Published 29 June 2020

Academic Editor: Shinji Miwa

Copyright (C) 2020 Michele Amaral da Silveira et al. This is an open access article distributed under the Creative Commons Attribution License, which permits unrestricted use, distribution, and reproduction in any medium, provided the original work is properly cited.

\begin{abstract}
Meningiomas are considered the most common intracranial tumors, affecting mainly women. Studies in mixed populations can be of great importance to clarify issues related to the genetic diversity of tumors and their development. Considering that data obtained from analyses of the profile of copy number alterations (CNA) have been a useful diagnostic indicator for many types of tumors and that meningiomas show a complex pattern of gains and losses in the number of copies, our objective was to analyze the CNA profile in 33 samples of meningiomas of different histological grades (WHO Grade I-III) from patients in a city located in the Amazon region of Brazil, using aCGH. We found that the female to male ratio was $3: 1$. The aCGH analysis revealed a total of 2304 CNA, with an average of $69.8 \pm 57.4$ per case, of which 1197 were gains (52\%), 926 were losses (40.2\%), 105 were amplifications (4. $5 \%$ ), and 76 were deletions (3.3\%). A significant relationship was observed between the type of CNA and the degree of the tumor (chi-square test: $\chi^{2}=65,844 ; p<0.0001$; contingency coefficient: $C=0.1772 ; p<0.0001$ ). Evaluating the recurrent changes in at least $50 \%$ of the samples, we observe as the most frequent losses of the segments 22q13.1-q13.2 (82\%), 1p35.3 (76\%), and 14q13.1q13.2 (67\%), involving all histopathological grades. The analysis of these regions showed the inclusion of genes with functions such as regulation, maintenance of cell survival, reorganization of the cytoskeleton, cell signaling, and DNA repair, among others. However, overall, the profiles observed in meningiomas of this admixed population were very similar to the ones observed in Caucasian groups. An interesting finding was a recurrent gain of 8 p22 observed only in grade I meningiomas, a region which includes DLC1, a suppressor candidate gene probably implicated in the developments or progression of meningiomas, usually found deleted, when related to CNAs.
\end{abstract}

\section{Introduction}

Meningiomas are among the most common of central nervous system (CNS) neoplasms, corresponding to more than a third of primary CNS neoplasms and being considered the most common intracranial tumors [1-3]. They arise from meningothelial arachnoid cells and are often attached to the internal surface of the dura mater $[4,5]$. They are mostly benign and slow growing, although a small proportion present malignant behavior, characterized by 
invasive growth patterns and/or significantly higher recurrence rates [6]. Meningiomas are more common in adults, accounting for $38 \%$ of intracranial tumors in women and $20 \%$ in men [7]. The incidence of meningiomas increases markedly after the age of 65 and with the aging of the population, and studies on this tumor are becoming increasingly prevalent in neuro-oncology [3].

The World Health Organization (WHO) classification categorizes meningiomas based on their histological characteristics and risk of recurrence, in three grades: I, benign (80\%), II, atypical (18\%), and III, anaplastic/malignant (2\%). Studies suggest that the aggressive behavior of some meningiomas is attributed to molecular changes, regardless of their histopathology, and histological aspects of each variant may indicate specific biomolecular changes $[2,8,9]$. Thus, it is opportune to understand and integrate the genomic findings that have the greatest impact in determining the clinical and biological behavior of meningiomas, aiming to incorporate them in the future, in the pathological classification of these tumors.

In the past few years, our understanding of meningioma biology, classification, grading, and molecular genetics have enabled the identification of recurring genetic and epigenetic alterations that are promising treatment targets $[2,10]$. In this sense, the analyses of the profile of copy number alterations (CNA) have shown that meningiomas are characterized by a complex pattern of gains and losses of segments harboring not only tumor suppressor genes and oncogenes but also candidate genes or genes with an already known role in tumorigenesis pathways [11, 12]. Several candidate genes are associated with tumorigenesis in meningiomas, with a complex pattern of gains and losses in the number of copies throughout the genome [13].

For instance, the most common CNAs in meningiomas involve chromosomes $22 \mathrm{q}$, which are found in the neurofibromatosis 2 (NF2) gene. Allelic losses (loss of heterozygosity $(\mathrm{LOH})$ ) of this region are found in $40-70 \%$ of sporadic and the vast majority of NF2 associated meningiomas. Additionally, NF2 mutations are found in up to $60 \%$ of tumors, consistent with a classic two-hit mechanism of tumor suppressor gene inactivation [2, 14-17]. Usually, it is proposed that meningiomas progress from low-grade to high-grade tumors, although this is not always easy to be demonstrated [18], and cytogenetic studies propose a higher amount of chromosomal gains and losses according to the grade of tumors [19-24]. Whence, while $\mathrm{LOH}$ at 22q12.2 represented an early event, gains or amplifications involving 1q, 9q, 12q, 15q, 17q, and 20q have been associated with higher grade [25-27].

An important aspect to consider is that it is becoming clear that some of the differences in cancer risk, incidence, and survival among people of different racial and ethnic backgrounds can be attributed to biological factors [28]. Hence, studies in admixed populations may have a great importance to clarify issues concerning the genetic diversity of tumors and its development, considering that most studies have been performed in Caucasians.

In this regard, Northern Brazilian populations are extremely interesting, because they are derived from the intermixture of Amerindians, Europeans, and Africans [28-30]. Moreover, Carvalho et al. [31] identified that meningiomas represented the second most frequent CNS tumor type in a public cancer hospital in the State of Pará, analyzing samples between 1997 and 2014. Based on this, our objective was to analyze the landscape of copy number alterations in samples of meningiomas from patients in a city located in the Amazon region of Brazil, considering that other studies involving non-mixed populations may not be applied to this. The results may show whether genomic alterations are common among Caucasian and miscegenated populations, or if they represent a different pattern in the latter, in view of the lack of this type of study in nonCaucasian populations.

\section{Material and Methods}

2.1. Patients. Thirty-three fresh tumor biopsies were evaluated, comprising primary meningioma tumors belonging to the three WHO malignancy grades, and collected between 2014 and 2018. Clinical data for each patient were obtained, and the summary of the characteristics is shown in Table 1. The present study was approved by the Ophir Loyola Hospital Ethical Committee (ID 593.717-0).

2.2. DNA Isolation. The DNA from biopsies was isolated using Illustra tissue and cells genomic Prep Mini Spin kit (GE Healthcare), according to the protocols provided by the supplier. The 260/280 and 260/230 ratios were determined by NanoDrop (Thermo Scientific) and the DNA was quantified using TapeStation (Agilent), using the supplier's protocol.

\subsection{Array Comparative Genomic Hybridization (aCGH).} Array comparative genomic hybridization (aCGH) using SurePrint G3 CGH + SNP Array $180 \mathrm{~K}$ platform (Agilent Technologies, CA, USA) was performed according to the Agilent Technologies protocol (Agilent Oligonucleotide Array-Based CGH for Genomic DNA Analysis Enzymatic Labeling for Blood, Cells, or Tissues, protocol v. 7.2, published in July 2012). In brief, $1 \mu \mathrm{g}$ of reference DNA (Agilent Euro Male/Female) and patient DNA was digested and labeled using the SureTag DNA Labeling kit (Agilent Technologies). After purification, labeled sample and reference DNA were cohybridized at $65^{\circ} \mathrm{C}$ for 16 hours to the array and washed and according to the supplier's default protocol. The slides were scanned and decoded by the software Feature Extraction v. 10.7 (Agilent Technologies), using the protocol CGH_107_Sep09.

2.4. Data Analyses. Data were visualized and analyzed by Agilent Cytogenomics 5.0 as described elsewhere [32]. Aberration statistical algorithm ADM-2, with threshold 6.0, was used for CNAs. Five-probe 0.15_log2 filter was used for aberration evaluation. For analyses, we considered CNAs found in two or more samples, which were organized using the software Excel (Microsoft). For the evaluation of gains or losses in the number of copies of DNA segments, only those that covered at least five consecutive oligonucleotides with 
TABLE 1: Patient information regarding sex, age, and histological classification of meningiomas.

\begin{tabular}{|c|c|c|c|c|}
\hline Sample ID & Sex & Age (years) & Histological type & Grade \\
\hline MNG 02 & Male & 25 & Transitional meningioma (mixed) & I \\
\hline MNG 06 & Male & 41 & Malignant meningioma (anaplastic) & III \\
\hline MNG 16 & Female & 61 & Fibroblastic meningioma with low cellularity and no mitotic activity & I \\
\hline MNG 23 & Male & 48 & Meningioma (clear cell type areas) & II \\
\hline MNG 26 & Female & 55 & Transitional meningioma & I \\
\hline MNG 32 & Male & 56 & Mixed meningioma & I \\
\hline MNG 37 & Female & 37 & Clear cell meningioma & II \\
\hline MNG 38 & Male & 31 & Meningothelial meningioma & I \\
\hline MNG 44 & Female & 46 & Meningothelial meningioma & I \\
\hline MNG 45 & Female & 46 & Transitional meningioma & I \\
\hline MNG 46 & Female & 48 & Fibroblastic meningioma & I \\
\hline MNG 54 & Female & 74 & Fibroblastic meningioma & I \\
\hline MNG 57 & Male & 41 & Atypical meningothelial meningioma & I \\
\hline MNG 66 & Female & 63 & Fibroblastic meningioma & I \\
\hline MNG 75 & Male & 46 & Syncytial meningioma & I \\
\hline MNG 77 & Male & 84 & Transitional meningioma & I \\
\hline MNG 78 & Female & 65 & Psammomatous meningioma & I \\
\hline MNG 81 & Female & 59 & Meningothelial meningioma & I \\
\hline MNG 83 & Female & 63 & Psammomatous meningioma & I \\
\hline MNG 84 & Male & 54 & Transitional meningioma & I \\
\hline MNG 98 & Female & 75 & Microcystic meningioma & I \\
\hline MNG 105 & Male & - & Meningioma* & \\
\hline MNG 112 & Male & 49 & Meningothelial meningioma & I \\
\hline MNG 119 & Female & 61 & Meningioma* & \\
\hline MNG 122 & Female & 55 & Fibroblastic meningioma & I \\
\hline MNG 123 & Female & 32 & Meningioma* & \\
\hline MNG 125 & Female & 57 & Mixed meningioma & I \\
\hline MNG 33 & Female & 40 & Hemangioblastic meningioma with cellularity of the forehead and mitotic index & I \\
\hline MNG 45 & Male & 40 & Meningothelial meningioma & I \\
\hline MNG 46 & Female & 17 & Meningothelial meningioma & I \\
\hline MNG 50 & Female & 51 & Meningothelial meningioma & I \\
\hline MNG 142 & Female & 45 & Meningothelial meningioma & I \\
\hline MNG 201 & Female & 29 & Meningioma* & \\
\hline
\end{tabular}

${ }^{*}$ Histological type was not reported. - , age was not informed.

$\log 2$ of the test/reference ratio $\geq 0.3$ or $\leq-0.3$ were considered as possible changes in the number of copies, gains and losses, respectively.

The proportions between the sexes were calculated using Fisher's exact test, considering $p<0.05$. The mean, median, standard deviation, and amplitude for the age variable were calculated. The comparison of the means between the ages by sex was performed using the Student's $t$-test. Pearson's correlation analysis was performed to verify whether there was a relationship between age and tumor grade according to the WHO. The chi-square test and the correlation test (verifying the association between variables) "contingency coefficient $C$," which is a nonparametric model that verifies the presence of associations between qualitative ordinal variables, were performed. The tests were used to verify whether there is a relationship between the type of CNA and the degree of the tumor according to the WHO. All statistical analyses were performed using the GraphPad Prism 8.0.2 (GraphPad Software; La Jolla, CA) software.

\section{Results}

3.1. Samples. We analyzed 33 fresh samples of meningiomas, of which twenty-one patients were females (64\%) and twelve patients were males $(36 \%)$ (Table 1$)$. The female to male ratio was $3: 1$, according to Fisher's exact test $(p<0.05)$. The ages ranged from 17 to 84 years, and the age of the MNG 105 case was not known. The total mean age was $49.8 \pm 14.9$ (Table 2). Student's $t$-test was used to compare the mean age according to gender, with the male gender being 46.8 and the female gender was 51.3, with $p=0,20$, demonstrating that there was no significant difference between them (Figure 1).

Of the thirty-three samples, twenty-six were classified as benign (grade I), two as grade II, and one sample as grade III. Four did not present information regarding the histological type (Table 3). Of those classified as grade I, nine were meningothelial, five were fibroblastic, four were transitional, two were psammomatous, three were mixed (with characteristics of two histological types), one was syncytial, one was microcytic, and one was hemangioblastic. Those classified as grade II were clear cell meningiomas and the one classified as grade III was anaplastic meningioma. There was no association between age and grade of the tumor $(p=0.2976)$. 
TABLE 2: Descriptive statistics of patient ages.

\begin{tabular}{lc}
\hline & Age \\
\hline Maximum & 84 \\
Minimum & 17 \\
Mean & 49.8 \\
Median & 48.5 \\
SD & 14.8 \\
Amplitude & 67 \\
Total & 32 samples \\
\hline
\end{tabular}

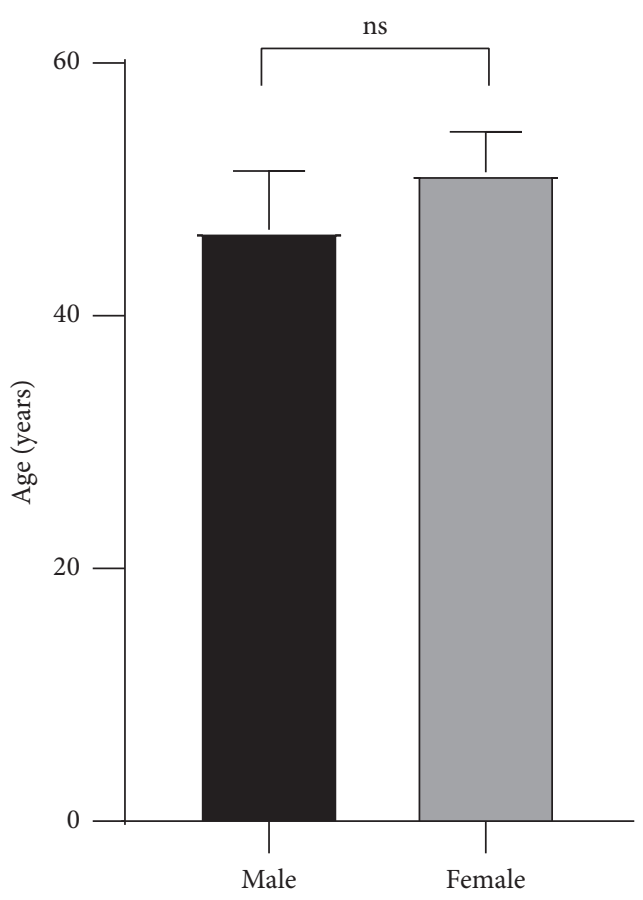

FIgURE 1: Average age for sex. Bars: mean with SEM.

3.2. Copy Number Alterations. aCGH analysis revealed a total of 2304 CNAs in the 33 samples of meningiomas evaluated, with an average of $69.8 \pm 57.4$ per case (ranging from 27 to 264), of which 1197 were gains (52\%), 926 were losses (40.2\%), 105 were amplifications (4.5\%), and 76 were deletions (3.3\%).

Table 4 shows the total number of CNAs according to histological grades, in which the gains were allocated with the amplifications, while losses were allocated with the deletions. It was found that grade I samples showed $60.3 \%$ gains/amplifications, grade II samples showed $79.6 \%$ gains/ amplifications, and grade III samples showed 73\% losses/ deletions.

A significant relationship was observed between the type of CNA and the degree of the tumor (chi-square test: $\chi^{2}=65,844 ; p<0.0001$; contingency coefficient: $C=0.1772$; $p<0.0001)$. Grade III sample showed more CNAs of losses/ deletions when compared to grades I and II, which presented more gains/amplifications (Figure 2).

Taking into account the recurrent CNAs in at least $50 \%$ of the studied samples, it was possible to identify a total of 85 CNAs, involving chromosomes $1,3,4,8,11,14,15,16,17$, and
TABLE 3: Information on patients regarding the degree of the tumor.

\begin{tabular}{lc}
\hline Grade & $N$ \\
\hline I & 26 \\
II & 2 \\
III & 1 \\
Not categorized & 4 \\
\hline
\end{tabular}

TABle 4: Total number of CNAs by histological grade.

\begin{tabular}{lccc}
\hline & $\begin{array}{c}\text { Gains/ } \\
\text { amplifications }\end{array}$ & $\begin{array}{c}\text { Losses/ } \\
\text { deletions }\end{array}$ & $\begin{array}{c}\text { Total number of } \\
\text { CNAs }\end{array}$ \\
\hline Grade I & 1078 & 707 & 1785 \\
Grade II & 125 & 32 & 157 \\
Grade & 24 & 65 & 89 \\
III & & & 8 \\
\hline
\end{tabular}

22. The most frequent CNAs were loss/deletion in $1 \mathrm{p}$ (1p35.3-76\%), 3q (3q29-54\%), 4p (4p14-57\%), 11q (11q23.3-51\%), 14q (14q13.1-q13.2-67\%), 15q (15q15.1-57\%), $16 \mathrm{q}(16 \mathrm{q} 22.1-54 \%)$, and 22q (22q13.1-q13.2-82\%) and gain/ amplification in 8p (8p.22-64\%), 14q (14q32.33-100\%), 16q (16q.21-51\%), and $17 \mathrm{q}$ (17q21.33-67\%).

The analysis of these regions showed the inclusion of genes with functions such as regulation, maintenance of cell survival, reorganization of the cytoskeleton, cell signaling, and DNA repair, among others, which are associated with the appearance of several types of pathologies. Table 5 highlights some of these genes found in these regions, correlated with the histological grade.

\section{Discussion}

We have profiled genomic CNAs of primary meningioma tumors belonging to the three WHO malignancy grades, with a total of 33 samples, in order to compare our results obtained from a miscegenated, genetically distinct population with other previous studies, which mostly include Caucasian populations. Overall, our results were very similar to other studies, not only concerning the characterization of the sample, such as sex ratio, age, and subtypes, but also considering the copy number alteration profile.

In what concern the general aspects of the samples, we found a 3:1 ratio between females and males, showing an average age of 49.8, similar to the findings by Mendes et al. [33], who found an average of 47 years and the highest number of women affected in a study conducted in Southern Brazil. Carvalho et al. [31], who analyzed the same population, also reported a greater number of women in the group of patients with meningiomas. Approximately $80 \%$ of the cases of meningiomas described in the literature are benign and correspond to grade I according to the current WHO classification, with the meningothelial subtype being the most frequent, followed by fibroblastic and transitional, which combines the two patterns mentioned above, with transitions between both [34]. Holleczek et al. [4] found in their study the proportion of $70 \%, 28 \%$, and $3 \%$ of 


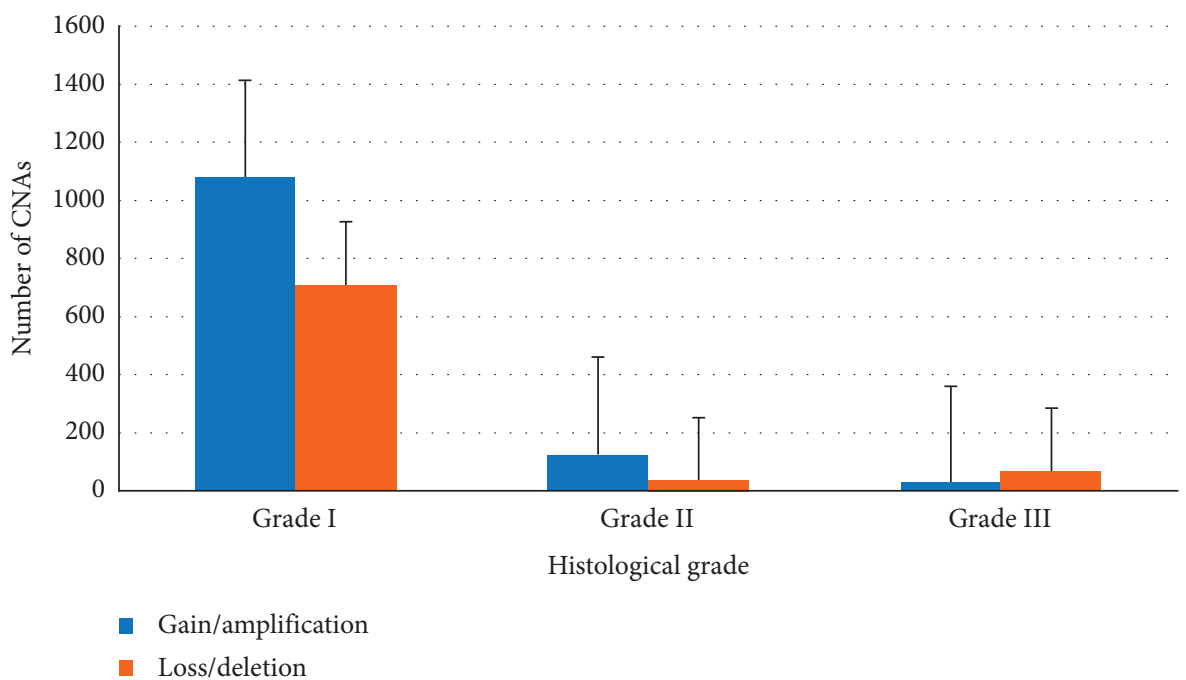

Figure 2: Type of CNA in relation to histological grade.

TABle 5: Some genes found in the most frequent altered cytobands in the analyzed meningioma samples correlating the histological grade.

\begin{tabular}{lcccc}
\hline Cytobands & Genes & $\begin{array}{c}\text { Histological } \\
\text { grade }\end{array}$ & $\begin{array}{c}\text { Type } \\
\text { of } \\
\text { CNA* }\end{array}$ & $\begin{array}{c}\text { Frequency } \\
\text { in the samples } \\
(\%)\end{array}$ \\
\hline 1p35.3 & $\begin{array}{c}\text { THEMIS2 } \\
\text { RPA2 }\end{array}$ & I, II, III & Loss & 76 \\
& SESN2 & & & \\
3q29 & RCC1 & & & \\
4p14 & PAK2 & I, III & Loss & 54 \\
8p22 & RFC1 & I, III & Loss & 57 \\
$11 \mathrm{q} 23.3$ & MSR1 & I & Gain & 64 \\
14q13.1- & CXCR5 & I, III & Loss & 51 \\
q13.2 & EAPP & I, II, III & Loss & 67 \\
14q32.33 & FAM30A & I, II, III & Gain & 100 \\
$15 q 15.1$ & CHAC1 & I, II, III & Loss & 57 \\
16q21 & CDH11 & I, II & Gain & 51 \\
16q22.1 & SF3B3 & I, III & Loss & 54 \\
17q21.33 & COL1A1 & I, II & Gain & 67 \\
22q13.1- & ST13 & I, II, III & Loss & 82 \\
q13.2 & TOB2 & & & \\
\hline
\end{tabular}

${ }^{*}$ Consider loss/deletion and gain/amplification.

meningiomas of grades I, II, and III, respectively, according to the WHO classification.

The population studied in the present study was mostly composed of grade I type and meningothelial subtype, followed by fibroblast, and these findings are similar to those found in other populations in relation to the frequency of the type of histological grade, despite the fact of being ethnically quite distinct of the population analyzed by those authors. There was no association between age and grade of the tumor. Sporadic meningiomas are characterized by several changes in the number of chromosomal copies, and it seems to increase with the degree and progression of the tumor [35-38]. We found a total of 2304 CNAs in the 33 samples of meningiomas evaluated, of which 1197 were gains (52\%),
926 were losses (40.2\%), 105 were amplifications (4.5\%), and 76 were deletions $(3.3 \%)$.

A significant relationship was observed between the type of CNA and the degree of the tumor, indicating that grade III presented more loss/deletion when compared to grades I and II. According to previous reports, atypical and anaplastic meningiomas include frequent loss of chromosomes $1 \mathrm{p}, 6 \mathrm{q}$, $10 \mathrm{q}, 14 \mathrm{q}$, and $18 \mathrm{q}$ and gain of chromosomes 1q, 9q, 12q, 15q, $17 \mathrm{q}$, and $20 \mathrm{q}$. Among these, the most frequent changes observed are losses in $1 \mathrm{p}$ and $14 \mathrm{q}$, apart from alterations in chromosome $22 \mathrm{q}$ which correspond to the most frequently observed ones in meningiomas, usually affecting the NF2 gene, and are present in half of grade II and almost all grade III meningiomas $[6,10,20]$. In the present study, taking into account the analyses carried out on CNAs present in at least $50 \%$ of the samples, we observed that the losses/deletions involved chromosomes 1p, 3q, 4p, 11q, 14q, 15q, 16q, and $22 \mathrm{q}$ and the gains/amplifications involved chromosomes $8 \mathrm{p}$, $14 \mathrm{q}, 16 \mathrm{q}$, and 17q. Most changes were found on chromosomes 22, 1, and 14, respectively, encompassing samples of all histopathological grades.

Among characterized genetic alterations, loss of an entire chromosome 22 is commonly reported in meningiomas and was among the first recurring cytogenetic alterations ever described in human solid tumors, even when meningiomas were studied by means of classical cytogenetics [39]. The importance of CNAs involving this chromosome remains evident, as they are detected in virtually all studies involving genomic analyses of meningiomas.

Concerning losses/deletions in $1 \mathrm{p}$, the most frequently identified one was 1 p35.3 (76\%), a region where we find several important genes, including SESN2 that encodes a protein that can act in the regulation of cell growth and survival and may still be involved in the cellular response to different stress conditions $[40,41]$. This CNA was found in samples of all histopathological grades and may be associated with the development and progression of meningiomas. In addition to this, it is worth noting the importance of 
molecular profile in the identification of subgroups of meningiomas. Hence, loss of RCC1 is associated with the development of microcystic meningioma, and this alteration was observed in one of our samples, classified as microcystic, a type which corresponds to $1 \%$ of all grade I meningiomas.

Most recurrent losses are related to regions containing genes related to tumor suppression pathways, while gains usually include potential oncogenes. Additionally, most alterations found in grade I tumors were also observed in grades II and III, suggesting they may be related to the process of initial development of meningiomas. The only recurrent alteration exclusive for grade I tumor was the gain of $8 \mathrm{p} 22$. Interestingly, this region is usually related to loss, as it harbors $D L C 1$, a suppressor candidate gene probably implicated in the developments or progression of meningiomas [42-45]. Hence, the correct sense of this amplification in a high proportion of grade I meningiomas remains unclear.

Overall, our results are similar to the landscape of copy number alterations described in other populations that are ethnically different, suggesting that meningiomas are not influenced by genetic variability related to ethnicities. In fact, the similarity of our findings with previous reports may be indicative of the relative importance of some of these CNAs as specific driver alterations, especially the ones identified markedly different across grades.

\section{Data Availability}

The complete results from the aCGH analyses, used to support the findings of this study, are included within the supplementary information file.

\section{Ethical Approval}

The present study was approved by the Ophir Loyola Hospital Ethical Committee (ID 593.717-0), Brazil.

\section{Conflicts of Interest}

The authors declare there that are no conflicts of interest.

\section{Authors' Contributions}

MAS and EHCO conceived the study and were in charge of overall direction and planning. JRNB and CKNA contributed to sample collection and preparation and were responsible for data curation. MAS, WASF, and FESS verified the analytical methods. MAS and FESS performed statistical analyses. MAS, WASF, and EHCO contributed to the interpretation of the results. MAS wrote the manuscript with input from FESS, WASF, and EHCO.

\section{Acknowledgments}

The authors are grateful to Instituto Evandro Chagas (Ananindeua, PA, Brazil) and Pró-Reitoria de Pesquisa e Pós-Graduação (PROPESP/UFPA, Belém, PA, Brazil) for financial and technical support and to Conselho Nacional de Desenvolvimento Científico e Tecnológico (CNPq) for
Michele Amaral da Silveira's Phd fellowship. This study was financed partly by Instituto Evandro Chagas/SVS/MS.

\section{Supplementary Materials}

Data sheet containing all the detected CNAs with respective chromosomal location, detected by aCGH in the multisample analyses. (Supplementary Materials)

\section{References}

[1] C. Mawrin, "Molekulare biologie, diagnostik und therapie von meningeomen," Der Pathologe, vol. 40, no. 5, pp. 514-518, 2019.

[2] A. Perry and D. J. Brat, Practical Surgical Neuropathology: A Diagnostic Approach in Pattern Recognition, Elsevier, Amsterdam, Netherlands, 2018.

[3] S. Suppiah, F. Nassiri, W. L. Bi et al., "Molecular and translational advances in meningiomas," Neuro-Oncology, vol. 21, no. 1, pp. i4-i17, 2019.

[4] B. Holleczek, D. Zampella, S. Urbschat et al., "Incidence, mortality and outcome of meningiomas: a population-based study from Germany," Cancer Epidemiology, vol. 62, Article ID 101562, 2019.

[5] M. Hayat, Tumors of the Central Nervous System: Meningiomas and Schwannomas, Springer Science \& Business Media, Berlin, Germany, 2012.

[6] W. L. Bi, Y. Mei, P. K. Agarwalla, R. Beroukhim, and I. F. Dunn, "Genomic and epigenomic landscape in meningioma," Neurosurgery Clinics of North America, vol. 27, no. 2, pp. 167-179, 2016.

[7] D. C. Weber, K.-O. Lovblad, and L. Rogers, "New pathology classification, imagery techniques and prospective trials for meningiomas: the future looks bright," Current Opinion in Neurology, vol. 23, no. 6, pp. 563-570, 2010.

[8] D. N. Louis, A. Perry, G. Reifenberger et al., "The 2016 World Health Organization classification of tumors of the central nervous system: a summary," Acta Neuropathologica, vol. 131, no. 6, pp. 803-820, 2016.

[9] G. Mohapatra, J. Sharma, and S. Yip, “Array CGH in brain tumors," Methods in Molecular Biology, vol. 973, pp. 325-338, 2013.

[10] M. Preusser, P. K. Brastianos, and C. Mawrin, "Advances in meningioma genetics: novel therapeutic opportunities," $\mathrm{Na}$ ture Reviews Neurology, vol. 14, no. 2, pp. 106-115, 2018.

[11] D.-C. Lin, M.-R. Wang, and H. P. Koeffler, "Genomic and epigenomic aberrations in esophageal squamous cell carcinoma and implications for patients," Gastroenterology, vol. 154, no. 2, pp. 374-389, 2018.

[12] M. Zarrei, J. R. MacDonald, D. Merico, and S. W. Scherer, “A copy number variation map of the human genome," Nature Reviews Genetics, vol. 16, no. 3, pp. 172-183, 2015.

[13] S. Yuzawa, H. Nishihara, and S. Tanaka, "Genetic landscape of meningioma," Brain Tumor Pathology, vol. 33, no. 4, pp. 237-247, 2016.

[14] M. H. Ruttledge, J. Sarrazin, S. Rangaratnam et al., "Evidence for the complete inactivation of the NF2 gene in the majority of sporadic meningiomas," Nature Genetics, vol. 6, no. 2, pp. 180-184, 1994.

[15] S. Lee, P. J. Karas, C. C. Hadley et al., "The role of merlin/NF2 loss in meningioma biology," Cancers, vol. 11, no. 11, p. 1633, 2019.

[16] N. Waldt, D. Scharnetzki, C. Kesseler et al., "Loss of PTPRJ/ DEP-1 enhances NF2/merlin-dependent meningioma 
development," Journal of the Neurological Sciences, vol. 408, Article ID 116553, 2020.

[17] P. Li, T. Wu, Y. Wang et al., "Clinical features of newly developed NF2 intracranial meningiomas through comparative analysis of pediatric and adult patients," Clinical Neurology and Neurosurgery, vol. 194, Article ID 105799, 2020.

[18] L. Carvalho, I. Smirnov, G. S. Baia et al., "Molecular signatures define two main classes of meningiomas," Molecular Cancer, vol. 6, no. 1, p. 64, 2007.

[19] R. G. Weber, J. Bostrom, M. Wolterss et al., "Analysis of genomic alterations in benign, atypical, and anaplastic meningiomas: toward a genetic model of meningioma progression," Proceedings of the National Academy of Sciences, vol. 94, no. 26, pp. 14719-14724, 1997.

[20] R. Ketter, S. Urbschat, W. Henn et al., "Application of oncogenetic trees mixtures as a biostatistical model of the clonal cytogenetic evolution of meningiomas," International Journal of Cancer, vol. 121, no. 7, pp. 1473-1480, 2007.

[21] D. E. Reuss, R. M. Piro, D. T. W. Jones et al., "Secretory meningiomas are defined by combined KLF4 K409Q and TRAF7 mutations," Acta Neuropathologica, vol. 125, no. 3, pp. 351-358, 2013.

[22] F. Sahm, J. Bissel, C. Koelsche et al., "AKT1E17K mutations cluster with meningothelial and transitional meningiomas and can be detected by SFRP1 immunohistochemistry," Acta Neuropathologica, vol. 126, no. 5, pp. 757-762, 2013.

[23] N. Paramasivam, D. Hübschmann, U. H. Toprak et al., "Mutational patterns and regulatory networks in epigenetic subgroups of meningioma," Acta Neuropathologica, vol. 138, no. 2, pp. 295-308, 2019.

[24] G. Jungwirth, Y. Tao, M. Mahmoud et al., "Identification of KIF11 as a novel target in meningioma," Cancers, vol. 11, no. 4 , p. $545,2019$.

[25] D. Gabeau-Lacet, D. Engler, S. Gupta et al., "Genomic profiling of atypical meningiomas associates gain of $1 \mathrm{q}$ with poor clinical outcome," Journal of Neuropathology \& Experimental Neurology, vol. 68, no. 10, pp. 1155-1165, 2009.

[26] W. Krupp, H. Holland, R. Koschny et al., "Genome-wide genetic characterization of an atypical meningioma by singlenucleotide polymorphism array-based mapping and classical cytogenetics," Cancer Genetics and Cytogenetics, vol. 184, no. 2, pp. 87-93, 2008.

[27] A.-F. Pelz, P. Klawunde, M. Skalej et al., "Novel chromosomal aberrations in a recurrent malignant meningioma," Cancer Genetics and Cytogenetics, vol. 174, no. 1, pp. 48-53, 2007.

[28] B. E. Henderson, N. E. Lee, V. Seewaldt, and H. Shen, "The influence of race and ethnicity on the biology of cancer," Nature Reviews Cancer, vol. 12, no. 9, pp. 648-653, 2012.

[29] A. L. D. S. Resende, I. E. Mattos, and S. Koifman, "Dieta e câncer gástrico: aspectos históricos associados ao padrão de consumo alimentar no estado do pará," Revista de Nutrição, vol. 19, no. 4, pp. 511-519, 2006

[30] F. M. Salzano and M. Sans, "Interethnic admixture and the evolution of latin American populations," Genetics and Molecular Biology, vol. 37, no. 1, pp. 151-170, 2014.

[31] L. E. W. D. Carvalho, J. S. Sarraf, A. A. P. Semblano et al., "Central nervous system tumours profile at a referral center in the Brazilian Amazon region, 1997-2014," PLoS One, vol. 12, no. 4, Article ID e0174439, 2017.

[32] W. A. S. Ferreira, C. K. N. Amorim, R. R. Burbano et al., "Genomic and transcriptomic characterization of the new human glioblastoma cell line AHOL1,”, 2019.

[33] G. A. Mendes, B. R. Ongaratti, and J. F. S. Pereira-Lima, "Epidemiologia de uma série de tumores primários do sistema nervoso central," Arquivos Brasileiros de Neurocirurgia: Brazilian Neurosurgery, vol. 33, no. 4, pp. 279-283, 2014.

[34] G. Collord, P. Tarpey, N. Kurbatova et al., "An integrated genomic analysis of anaplastic meningioma identifies prognostic molecular signatures," Scientific Reports, vol. 8, no. 1, pp. 1-13, 2018.

[35] M. Tabernero, M. Jara-Acevedo, A. B. Nieto et al., "Association between mutation of the NF2gene and monosomy 22 in menopausal women with sporadic meningiomas," $B M C$ Medical Genetics, vol. 14, no. 1, p. 114, 2013.

[36] S. Rienstein, D. Loven, O. Israeli et al., "Comparative genomic hybridization analysis of radiation-associated and sporadic meningiomas," Cancer Genetics and Cytogenetics, vol. 131, no. 2, pp. 135-140, 2001.

[37] Y. Shen, F. Nunes, A. Stemmer-Rachamimov et al., "Genomic profiling distinguishes familial multiple and sporadic multiple meningiomas," BMC Medical Genomics, vol. 2, no. 1, p. 42, 2009.

[38] P. G. Buckley, C. Jarbo, U. Menzel et al., "Comprehensive DNA copy number profiling of meningioma using a chromosome 1 tiling path microarray identifies novel candidate tumor suppressor loci," Cancer Research, vol. 65, no. 7, pp. 2653-2661, 2005.

[39] K. Zang, "Meningioma: a cytogenetic model of a complex benign human tumor, including data on 394 karyotyped cases," Cytogenetic and Genome Research, vol. 93, no. 3-4, pp. 207-220, 2001

[40] M. Sánchez-Álvarez, R. Strippoli, M. Donadelli, A. V. Bazhin, and M. Cordani, "Sestrins as a therapeutic bridge between ROS and autophagy in cancer," Cancers, vol. 11, no. 10, p. $1415,2019$.

[41] A. V. Budanov, "Sestrins link tumor suppressors with the AMPK-TOR signaling network," Protein Phosphorylation in Human Health, p. 51, Intech Open, London, UK, 2012.

[42] G. R. Hankins, T. Sasaki, A.-S. Lieu et al., "Identification of the deleted in liver cancer 1 gene, DLC1, as a candidate meningioma tumor suppressor," Neurosurgery, vol. 63, no. 4, pp. 771-781, 2008.

[43] C. Mawrin and A. Perry, "Pathological classification and molecular genetics of meningiomas," Journal of Neuro-Oncology, vol. 99, no. 3, pp. 379-391, 2010.

[44] M. Bujko, P. Kober, N. Rusetska et al., "Aberrant DNA methylation of alternative promoter of DLC1 isoform 1 in meningiomas," Journal of Neuro-Oncology, vol. 130, no. 3, pp. 473-484, 2016.

[45] M. H. Pham, G. Zada, G. M. Mosich et al., "Molecular genetics of meningiomas: a systematic review of the current literature and potential basis for future treatment paradigms," Neurosurgical Focus, vol. 30, no. 5, p. E7, 2011. 